TITLE:

\title{
Sand ornaments used to attract females are avoided by rival males in the fiddler crab Uca lactea
}

$\operatorname{AUTHOR}(S)$ :

Muramatsu, Daisuke

CITATION:

Muramatsu, Daisuke. Sand ornaments used to attract females are avoided by rival males in the fiddler crab Uca lactea. Ethology Ecology \& Evolution 2017, 29(5): 501-510

ISSUE DATE:

2017

URL:

http://hdl.handle.net/2433/267983

\section{RIGHT:}

This is an Accepted Manuscript of an article published by Taylor \& Francis in Ethology Ecology \& Evolution on 10 Nov 2016, available online: http://www.tandfonline.com/10.1080/03949370.2016.1243156.; The full-text file will be made open to the public on 10 Nov 2017 in accordance with publisher's 'Terms and Conditions for Self-Archiving'.; This is not the published version. Please cite only the published version.この論文は出版社版でありません。引用の際には出版社 版をご確認ご利用ください。 
Sand ornaments used to attract females are avoided by rival males in the fiddler crab Uca lactea

DAISUKE MURAMATSU ${ }^{1}$

${ }^{1}$ Wildlife Research Center, Kyoto University, 2-24 Sekiden, Tanaka, Sakyo, Kyoto, 606-8203, Japan

(E-mail: muramatsu@wrc.kyoto-u.ac.jp)

Running heads: Ornaments to attract females are avoided by rival males 
Males of several fiddler crab species sometimes construct sand structures at the entrances to their burrows to which they attract females for mating. Sand structures are thought to exploit fiddler crabs' risk reducing behaviour by enticing them into the burrows, so males as well as females are expected to be attracted by the structures. Males with structures may thus incur greater costs to repel intruding males than males without structures, and only males that can afford such costs are likely to build structures. Given that the sand structures are constructed only by males that have sufficient ability to fend off intruders, other crabs may regard the structures as an indicator of those males' potential fighting ability. In the present study, I showed that burrowless males of Uca lactea were averse to burrows with structures when there were no predators nearby, but that burrowless females showed no such tendency. Sand structures in fiddler crabs may have originated as a sensory trap to attract females, but other males may use the structure as an indicator of the resident male's fighting ability. However, the sand structures did not appear to function as a signal to attract females.

KEY WORDS: ornament, signal, sensory trap, sand structure, hood, fiddler crab, Uca lactea.

\section{INTRODUCTION}

Sexual selection can often result in the evolution of costly signals that may serve as honest indicators of signaller quality (ZAHAVI 1975). An elaborate ornament, for example, would incur physiological costs for the signaller to produce and maintain the ornament (WALTHER \& CLAYTON 2004), so only high-quality individuals would be able to have such an ornament. The cost of the signal may also be social if the signaller is more likely to be attacked or harassed by conspecifics (ZUK 1991). In this case, the signal itself need not be costly to produce because the social cost ensures the signal's honesty.

Males of at least 18 species of fiddler crabs $(U c a)$ construct sand structures at the entrances to their burrows (CHRISTY \& BACKWELL 2006) in order to attract females into the burrows for mating (CHRISTY 1988; CHRISTY et al. 2003a, b). The fact that better-fed males construct such structures more often (BACKWELL et al. 1995; KIM \& CHOE 2003) suggests that structures may be energetically expensive and thus may act as an indicator of condition-dependent male quality (BACKWELL et al. 1995; CHRISTY et al. 2001). Although structure construction itself does not appear to be energetically expensive (CHRISTY 1988; BACKWELL et al. 1995; YAMAGUCHI et al. 2005), the possession of structures alone can be costly, and burrow residents will even destroy 
their own or experimentally planted structures (MURAMATSU 2009). This could be due to some social costs associated with possessing rather than constructing a structure (CHRISTY 1988), and only males that can afford such costs are able to keep structures (MurAmATSu 2010a).

It has been demonstrated in several fiddler crab species that sand structures function as sensory traps that exploit the predator-avoidance response of females to entice them into males' burrows (CHRISTY 1995; CHRISTY et al. 2003a, b). In the field, some male crabs are burrowless, either because they have left their burrows voluntarily or because they have been evicted by other crabs (MURAI et al. 1987; YAMAGUCHI 2001; How et al. 2007). Burrowless males may be searching for an empty burrow or attempting to take over a burrow from residents (POPE 2005; MURAMATSU 2011b), while burrowless females may be searching for a mate or an empty burrow (CHRISTY et al. 2003b; ZEIL et al. 2006). Many species of fiddler crabs approach objects to reduce predation risk when they leave their burrows (CHRISTY 1995; CHRISTY et al. 2003a; KIM et al. 2007, 2009). Therefore, burrowless crabs would be attracted by sand structures because the structures mimic protruding objects that crabs approach to reduce predation risk (CHRISTY et al. 2003b). Because sand structures elicit crabs' general risk reducing behaviour, structures should attract both sexes of burrowless crabs (CHRISTY 1988; BACKWELL et al. 1995; CHRISTY et al. 2003a). Indeed, CHRISTY (1995) showed that both sex of $U$. beebei differentially orient to burrows with structures than those without when frightened by a model bird predator. Males that have structures may thus incur greater costs than males without structures due to the need to repel intruding crabs other than receptive females (CHRISTY 1988; BACKWELL et al. 1995). Indeed, small males and males that have lost their large claws construct structures less frequently because these males have disadvantages in male-male contests (MURAMATSU 2010a).

Given that sand structures are constructed only by males that have sufficient ability to fend off intruders, other crabs may use the structures as an indicator of those males' potential fighting ability. When a resident male had a sand structure at the entrances to his burrow, burrowless males may keep away from the male because males with sand structures would be more formidable than males without structures. By contrast, burrowless females would have no reason to avoid males with structures because males rarely exhibit aggressive behaviour towards females in the breeding season (MURAMATSU 2011a). In fact, mate-searching females might selectively enter the burrows with structures if they prefer mating with males of greater fighting ability.

In the present study, I conducted field experiments to test whether male and female burrowless crabs responded differently to burrows with sand structures than to those without. I placed enclosures in a wild population of Uca lactea to fence out 
predators (predaceous crabs) and observed the behaviour of male and female burrowless crabs released within the enclosure. If sand structures are perceived as an indicator of fighting ability and if females find that comparatively attractive, burrowless males would visit burrows with structures less frequently but burrowless females would visit them more frequently.

\section{METHODS}

The data were collected in a dense colony of $U$. lactea, approximately $3500 \mathrm{~m}^{2}$ in area and centred on an intertidal mudflat in the estuary of the Yabusa River, Kagoshima, Japan $\left(31^{\circ} 41^{\prime} \mathrm{N}, 130^{\circ} 17^{\prime} \mathrm{E}\right)$. There were no distinct avian predators during observation, but some predaceous crabs, Helice japonica, occasionally preyed on $U$. lactea. Crabs emerged from their burrows and were active on the mudflat surface during diurnal low tides, and approximately $45 \%$ of males constructed sand structures at the entrances to their burrows (Fig. 1) (MURAMATSU 2010b).

The following experiments were conducted during spring tides from June to August 2005, except on days with heavy rain, which inhibited the crabs' surface activity. Each day, a wooden enclosure $\left(50 \times 50 \mathrm{~cm}^{2}\right.$ and $7 \mathrm{~cm}$ in height $)$ was placed on the mudflat to fence in three males with a structure and three males without a structure. The enclosure was high enough so that the crabs were visually and physically isolated from the rest of the population. Crabs other than these six resident males were removed from the enclosure and their burrows were covered with soil to obliterate the entrances. Crabs were captured by blocking their return to their burrows with a wooden stick (see MurAmATSU 2010a for details). Two burrowless males or two burrowless females were then captured at the study site and released in the enclosure after measuring their carapace width with callipers; the enclosures with a pair of either females or males were videotaped for $1 \mathrm{hr}$ immediately after lowest tide. These videotaped spots were marked with 1-m-long, 4-mm-diameter wooden poles, which were placed vertically into the sediment, leaving approximately $5 \mathrm{~cm}$ above the surface. The area surrounding the pole (an approximately $3 \mathrm{~m}$ radius) was not used again for the experiment.

Each burrowless crab was tracked on video; the number of burrows visited and whether they had structures were recorded. I also noted whether the resident was on the mudflat surface within $30 \mathrm{sec}$ before the focal burrowless male visited the burrow. Burrowless crabs may insert their walking legs or partially enter a burrow (check) or descend into a burrow until they disappear from the surface (enter). In cases where the sand structures were constructed or destroyed, or irrelevant crabs emerged from the mudflat during observation, the data were discarded.

To test for the effect of a sand structure on male and female responses, the 
number of times the focal crab checked or entered burrows with or without structures was analysed using the glmer (generalised linear mixed-effects models) of the lme4 package implemented in the statistical package $\mathrm{R}$ (R CORE TEAM 2016). The number of visits - check or enter — was used as the response variable, while whether each visited burrow had a structure — present or absent — and the carapace width of the burrowless crab ( $\mathrm{mm})$ were fitted as explanatory variables. The Poisson distribution with log link function was used to run a count regression. To account for inter-individual and interenclosure variations in the model, I used the IDs of burrowless crabs and enclosures as the random factors. I then calculated the Akaike information criterion (AIC; see AKAIKE 1974) values for all combinations of explanatory variables; the model that yielded the smallest AIC value was selected as the best model.

\section{RESULTS}

\section{Burrow visits by burrowless males}

A total of 10 burrowless males were successfully observed. Burrowless males visited one to eight burrows of resident males in $1 \mathrm{hr}$. Four burrowless males dug a burrow and one male stayed in it. No burrowless male succeeded in evicting the resident during the experiments. In one case, a burrowless male rushed to a burrow without a sand structure and the resident quickly escaped into his burrow. I counted this as "check" because the burrowless male inserted his walking legs into the burrow, though the male may have tried to enter or rob the burrow. In five cases, resident males performed courtship display ("lateral-circular waving"; see Muramatsu 2011b) and receded into their burrows as if they were trying to attract females into their burrows. Three burrowless males followed the residents and entered their burrows with structures, and others only checked the burrow-one with a structure and another without.

Burrowless males checked $0.20 \pm 0.13$ (mean \pm SE) burrows with structures and $1.50 \pm 0.56$ burrows without structures (Fig. 2). Based on AIC model selection, the best model contained the presence of a structure as the explanatory variable, but the size of the burrowless male was rejected (Table 1a). Within $30 \mathrm{sec}$ before burrowless males checked burrows, $47 \%$ (8/17) of the residents stayed in the burrow and were not visible to the burrowless males.

Burrowless males entered $0.80 \pm 0.20$ burrows with structures and $0.70 \pm 0.21$ burrows without structures (Fig. 2). The effects of sand structures and the size of the burrowless male were rejected, and the null model was selected as the best model (Table 1b). Within $30 \mathrm{sec}$ before burrowless males entered burrows, 80\% (12/15) of the residents stayed in the burrow. Thus, except for three residents that performed courtship 
display, all residents were in their burrow and were not visible to burrowless males.

\section{Burrow visits by burrowless females}

A total of 20 burrowless females were successfully observed. Burrowless females visited zero to 17 burrows of resident males in $1 \mathrm{hr}$; one female dug two burrows by herself but did not remain in either.

Burrowless females checked $0.70 \pm 0.50$ burrows with structures and $0.90 \pm$ 0.38 burrows without structures (Fig. 2). Based on AIC model selection, the effects of sand structures and size of burrowless female were rejected and the null model was selected as the best model (Table 1c).

Burrowless females entered $0.80 \pm 0.35$ burrows with structures and $0.50 \pm 0.18$ burrows without structures (Fig. 2). Again, the effects of sand structures and size of the burrowless female were rejected and the null model was selected as the best model, but the differences in AIC values were relatively small in this case (Table 1d). Three (18.8\%) burrows with structures and one $(10.0 \%)$ burrow without a structure were closed after a female entered them.

\section{DISCUSSION}

The results showed that male and female burrowless crabs do respond differently to burrows with and without structures, but the size of burrowless males and females had only weak effects on the number of burrow visits for both checking and entering; in all cases, the explanatory variable was dropped by model selection. Burrowless females checked burrows with and without structures at similar frequencies, whereas burrowless males checked burrows with structures 7.5 times less frequently than burrows without structures, suggesting that burrowless males were averse to burrows with structures. This tendency was supported by glmer analyses: the best model to predict the number of checks by burrowless males contained the presence of sand structures as the explanatory variable. It is also possible that burrowless males may have checked burrows with structures less often because the residents at these burrows were more aggressive to them. In a previous study, however, MURAMATSU (2011b) showed that resident males with structures perform aggressive lateral-flick waving less frequently, possibly because the territories around burrows with structures are less likely to be intruded into by other crabs and consequently the residents do not need to perform this waving frequently. If the apparent aggressiveness were important for the decision-making of burrowless males, they would avoid visiting burrows without structures. In reality, burrowless males avoid checking burrows with structures, suggesting that burrowless males predicted that residents with structures were more 
formidable than those without structures. By contrast, burrowless males entered burrows with and without structures at similar frequencies, so the null model was selected as the best model. Burrowless females entered burrows with a structure 1.6 times more frequently than burrows without structures, but the effect of sand structures was dropped by the process of model selection and the null model was selected as the best model.

Burrowless crabs wandering on the mudflat surface are at risk of predation (KoGA et al. 1998; Kim et al. 2007). Burrows that are occupied by other crabs may be beneficial for burrowless crabs because these burrows can be used as temporary shelters from predators, even though burrowless males and non-receptive females would likely be goaded into leaving later. Hence, they are likely to visit several burrows to check potential shelters that might be used when they encounter a predator. Burrowless crabs are able to rush back to previously visited burrows because fiddler crabs use path integration for homing (ZEIL 1998) and they would have to reset the "home" at each burrow in order to escape quickly. Moreover, burrowless crabs may be able to find a new burrow without conflict because of the presence of abandoned burrows in their habitat. Hence, it is worth entering burrows when there is no resident crab at the burrow entrance.

For burrowless males, it may not be easy to visit other crabs' burrows when the residents are on burrow surveillance because the burrow residents would attempt to repel them (MURAMATSU 2011a, b). Burrowless males may avoid visiting burrows when they detect a resident with a sand structure, because males with sand structures would be more formidable than males without them. Sand structures also indicate the sex of burrow residents because females do not construct structures (YAMAGUCHI 1970; MURAMATSU 2010b). Again, burrows without structures are expected to be safer for burrowless males because females do not have the enlarged claw that is an effective weapon in contests (MURAMATSU \& KOGA 2016). Indeed, burrowless males checked burrows with structures less frequently than burrows without structures. Interestingly, however, burrowless males entered burrows with and without structures at similar frequencies. These burrowless males may have been trying to find an abandoned burrow by entering burrows when they were uncertain whether the burrow was occupied or not. Indeed, the residents were in the burrow and were not visible to the burrowless males, except for three cases in which the residents performed courtship display. These resident males may have mistakenly performed courtship display towards burrowless males, as shown in MURAMATSU (2011a). However, there is no obvious reason why three burrowless males entered the burrows of courting resident males. Although there is no evidence, it might be possible that burrowless males can 
deceive residents and snatch the burrow by mimicking females (see BOOKSMYTHE et al. 2010). Burrowless females, by contrast, would be able to visit any male burrow without difficulty because both males with and males without structures attempt to attract females into their burrows (CHRISTY 1982; GREENSPAN 1982; YAMAGUCHI et al. 2005). Indeed, burrowless females checked burrows with or without structures at similar frequencies. Burrowless females likely checked these burrows in order to reset their home for path integration. Although I predicted that burrowless females would selectively enter the burrows with structures when they were searching for mates, the mean number of the burrows entered by burrowless females did not differ significantly with the presence or absence of a sand structure. Furthermore, at least one female stayed in a burrow without a structure and plugged the entrance, which indicates mating (YAmAguchi 1998, 2001; CHRISTY et al. 2001). Thus, the presence of sand structures, or resident males' current fighting abilities, might not be crucially important for matesearching females. Alternatively, burrowless females may not have been searching for mates. Displacement by males often provides the reason why females are burrowless, and there are many burrowless females with immature ovaries (MURAI et al. 1987). If this were the case, females would enter any burrow with or without a structure to obtain shelter.

It has been shown that burrowless females are attracted by stones, pieces of wood, shells (CHRISTY et al. 2003b), and even other species' sand structures (CHRISTY et al. 2003a). These results indicate that female responses are based not on reproductive benefits but on direct survival benefits (CHRISTY 1995; Kim et al. 2007, 2009), suggesting that the structures function as sensory traps (CHRISTY 1995). When a predator arrives, all resident crabs retreat into their burrows and thus all burrows with and without structures are turned into beneficial shelters. In this event, burrowless crabs have two choices: rush back to a confirmed burrow using path integration, or run to the nearest shelter using visual guidance. In the latter case, both sexes of burrowless crabs would be attracted by sand structures, either because they perceive the structure as a cue for a burrow entrance, or minimally as a protruding object that can be used as a temporary shelter.

Sensory traps are inherently deceptive; however, if only high-quality males can produce the signal and females prefer to mate with the males that have this signal, a signal that originated as a sensory trap could evolve into an honest signal of male quality (GARCIA \& RAMIREZ 2005; STUART-FOX 2005). In the case of Uca lactea, burrowless males may have used the sand structure as an indicator of the resident male's potential fighting ability, because burrowless males were averse to checking burrows with structures. Burrowless females, however, did not appear to use a structure 
as an indicator of male quality, because they did not selectively enter burrows with structures. Sand structures may not be important for mate-searching females because the male's current condition (such as fighting abilities) does not reflect heritable genetic qualities.

\section{ACKNOWLEDGEMENTS}

I would like to thank M. Imafuku and A. Mori for providing helpful comments on this study. I also thank E. Nakajima for editing the manuscript's English.

\section{FUNDING}

This research was financially supported in part by the Global Center of Excellence Program "Formation of a Strategic Base for Biodiversity and Evolutionary Research: from Genome to Ecosystem" of the Ministry of Education, Culture, Sports and Technology (MEXT), Japan.

\section{REFERENCES}

AKAIKE H. 1974. A new look at the statistical model identification. IEEE Trans Automat Contr. 19:716-723.

BACKWEll PRY, Jennions MD, Christy JH, Schober U. 1995. Pillar building in the fiddler crab Uca beebei: evidence for a condition-dependent ornament. Behav Ecol Sociobiol. 36:185-192.

Booksmythe I, MiLner RNC, JenNions MD, BACKWELl PRY. 2010. How do weaponless male fiddler crabs avoid aggression? Behav Ecol Sociobiol. 64:485-491.

CHRISTY JH. 1982. Burrow structure and use in the sand fiddler crab, Uca pugilator (Bosc). Anim Behav. 30:687-694.

CHRISTY JH. 1988. Pillar function in the fiddler crab Uca beebei (2): competitive courtship signaling. Ethology. 78:113-128. 
CHRIsTy JH. 1995. Mimicry, mate choice, and the sensory trap hypothesis. Am Nat. 146:171-181.

CHRISTY JH, BACKWELL PRY. 2006. No preference for exaggerated courtship signals in a sensory trap. Anim Behav. 71:1239-1246.

CHRISTY JH, BACKWELl PRY, Goshima S. 2001. The design and production of a sexual signal: hoods and hood building by male fiddler crabs Uca musica. Behaviour. 138:1065-1083.

CHRISTY JH, BACKWELL PRY, SCHOBER U. 2003a. Interspecific attractiveness of structures built by courting male fiddler crabs: experimental evidence of a sensory trap. Behav Ecol Sociobiol. 53:84-91.

Christy JH, BAUM JK, BACKWELl PRY. 2003b. Attractiveness of sand hoods built by courting male fiddler crabs, Uca musica: test of a sensory trap hypothesis. Anim Behav. 66:89-94.

GARCIA CM, RAMIREZ E. 2005. Evidence that sensory traps can evolve into honest signals. Nature. 434:501-505.

GREENSPAN BN. 1982. Semi-monthly reproduction cycles in male and female fiddler crab, Uca pugnax. Anim Behav. 30:1084-1092.

How MJ, Zeil J, Hemmi JM. 2007. Differences in context and function of two distinct waving displays in the fiddler crab, Uca perplexa (Decapoda: Ocypodidae). Behav Ecol Sociobiol. 62:137-148.

Kim TW, CHOE JC. 2003. The effect of food availability on the semilunar courtship rhythm in the fiddler crab Uca lactea (De Haan) (Brachyura: Ocypodidae). Behav Ecol Sociobiol. 54:210-217.

Kim TW, Christy JH, CHOE JC. 2007. A preference for a sexual signal keeps females safe. PLoS ONE. 2:1-4.

Kim TW, Christy JH, Dennenmoser S \& ChOE JC. 2009. The strength of a female 
mate preference increases with predation risk. Proc R Soc Lond B. 276:775-780.

Koga T, BACKWELl PRY, JENNIONS MD, CHRISTY JH. 1998. Elevated predation risk changes mating behaviour and courtship in a fiddler crab. Proc R Soc Lond B. 265:1385-1390.

Murai M, Goshima S, Henmi Y. 1987. Analysis of the mating system of the fiddler crab, Uca lactea. Anim Behav. 35:1334-1342.

MuRAMATSU D. 2009. To build or not to build - or to destroy burrow hoods in a population of Uca lactea. J Crust Biol. 29:290-292.

MuRAMATSU D. 2010a. Temporary loss of a sexual signal (claw loss) affects the frequency of sand structure construction in the fiddler crab, Uca lactea. Ethol Ecol Evol. 22:87-93.

MuRAMATSU D. 2010b. Sand structure construction in Uca lactea (De Haan, 1835) is related to tidal cycle but not to male or female densities. Crustaceana. 83:29-37.

MURAMATSU D. 2011a. For whom the male waves: four types of claw-waving display and their audiences in the fiddler crab, Uca lactea. J Ethol. 29:3-8.

MuRAmATSU D. 2011b. The function of the four types of waving display in Uca lactea: Effects of audience, sand structure, and body size. Ethology. 117:408-415.

Muramatsu D, Koga T. 2016. Fighting with an unreliable weapon: opponent choice and risk avoidance in fiddler crab contests. Behav Ecol Sociobiol. 70:713-724

POPE DS. 2005. Waving in a crowd: fiddler crabs signal in networks. In: McGregor PK, editor. Animal communication networks. Cambridge: Cambridge University Press; $p$. 252-276.

R CORE TEAm. 2016. R: A language and environment for statistical computing. Vienna, Austria: R Foundation for Statistical Computing. Available from: https://www.Rproject.org/

STUART-Fox D. 2005. Deception and the origin of honest signals. Trends Ecol Evol. 
20:521-523.

YAmaguchi T. 1970. Ecology of a fiddler crab (Uca lactea) (I). Calanus. 2:5-30.

YAMAGUCHI T. 1998. Evidence of actual copulation in the burrow in the fiddler crab, Uca lactea (De Haan, 1835) (Decapoda, Brachyura, Ocypodidae). Crustaceana. 71:565570.

YAMAGUCHI T. 2001. The mating system of the fiddler crab, Uca lactea (Decapoda, Brachyura, Ocypodidae). Crustaceana. 74:389-399.

YAMAGUChI T, HENMi Y, TABATA S. 2005. Hood building and territory usage in the fiddler crab, Uca lactea (De Haan, 1835). Crustaceana. 78:1117-1141.

WALTHER BA, CLAYTON DH. 2004. Elaborate ornaments are costly to maintain: evidence for high maintenance handicaps. Behav Ecol. 16:89-95.

ZAHAVI A. 1975. Mate selection - a selection for a handicap. J Theor Biol. 53:205-214.

ZEIL J. 1998. Homing in fiddler crabs (Uca lactea annulipes and Uca vomeris: Ocypodidae). J Comp Physiol A. 183:367- 377.

ZeIl J, Hemmi JM, BACKwell PRY. 2006. Fiddler crabs. Curr Biol. 16:40-41.

ZUK M. 1991. Sexual ornaments as animal signals. Trends Ecol Evol. 6:228-231. 
Table 1.

Values of the Akaike information criterion (AIC), ranked in increasing order, calculated from generalised linear mixed models for predicting the number of burrow visits.

\begin{tabular}{|c|c|c|c|c|}
\hline \multirow[b]{2}{*}{ Rank } & \multirow[b]{2}{*}{ AIC } & \multicolumn{3}{|c|}{ Parameter estimate $\pm \mathrm{SE}$} \\
\hline & & Intercept & $\begin{array}{c}\text { Sand structure } \\
\text { (present) }\end{array}$ & $\begin{array}{c}\text { Carapace width of } \\
\text { burrowless crab }\end{array}$ \\
\hline \multicolumn{5}{|c|}{ (a) Check by burrowless male } \\
\hline 1 & 52.6 & $0.166 \pm 0.481$ & $-2.015 \pm 0.753$ & - \\
\hline 2 & 54.2 & $-2.738 \pm 4.806$ & $-2.015 \pm 0.753$ & $0.202 \pm 0.330$ \\
\hline 3 & 61.9 & $-0.402 \pm 0.473$ & - & - \\
\hline 4 & 63.5 & $-3.305 \pm 4.806$ & - & $0.202 \pm 0.330$ \\
\hline \multicolumn{5}{|c|}{ (b) Enter by burrowless male } \\
\hline 1 & 47.4 & $-0.288 \pm 0.258$ & - & - \\
\hline 2 & 49.1 & $2.014 \pm 3.950$ & - & $-0.161 \pm 0.277$ \\
\hline 3 & 49.3 & $-0.357 \pm 0.378$ & $0.134 \pm 0.518$ & - \\
\hline 4 & 51.0 & $1.945 \pm 3.960$ & $0.134 \pm 0.518$ & $-0.161 \pm 0.277$ \\
\hline \multicolumn{5}{|c|}{ (c) Check by burrowless female } \\
\hline 1 & 83.9 & $-1.990 \pm 0.957$ & - & - \\
\hline 2 & 85.4 & $-1.872 \pm 0.969$ & $-0.251 \pm 0.356$ & - \\
\hline 3 & 85.5 & $-7.486 \pm 9.266$ & - & $0.400 \pm 0.664$ \\
\hline 4 & 87.0 & $-7.368 \pm 9.266$ & $-0.251 \pm 0.356$ & $0.400 \pm 0.664$ \\
\hline \multicolumn{5}{|c|}{ (d) Enter by burrowless female } \\
\hline 1 & 89.2 & $-1.273 \pm 0.594$ & - & - \\
\hline 2 & 89.4 & $-9.112 \pm 5.770$ & - & $0.582 \pm 0.419$ \\
\hline 3 & 89.8 & $-1.535 \pm 0.644$ & $0.470 \pm 0.403$ & - \\
\hline 4 & 90.0 & $-9.374 \pm 5.775$ & $0.470 \pm 0.403$ & $0.582 \pm 0.418$ \\
\hline
\end{tabular}


Fig. 1. - Male crab with a sand structure. During the breeding season, approximately $45 \%$ of male crabs build sand structures at the entrances to their burrows.

Fig. 2. - The mean number of burrows with or without sand structures visited by burrowless males and females. "Check" indicates that burrowless crabs insert their walking legs into the burrows or partially enter the burrows. "Enter" indicates that the burrowless crabs descend into the burrows until they disappear from the mudflat surface. An asterisk indicates that the best model in Table 1 contains the effect of sand structure. 


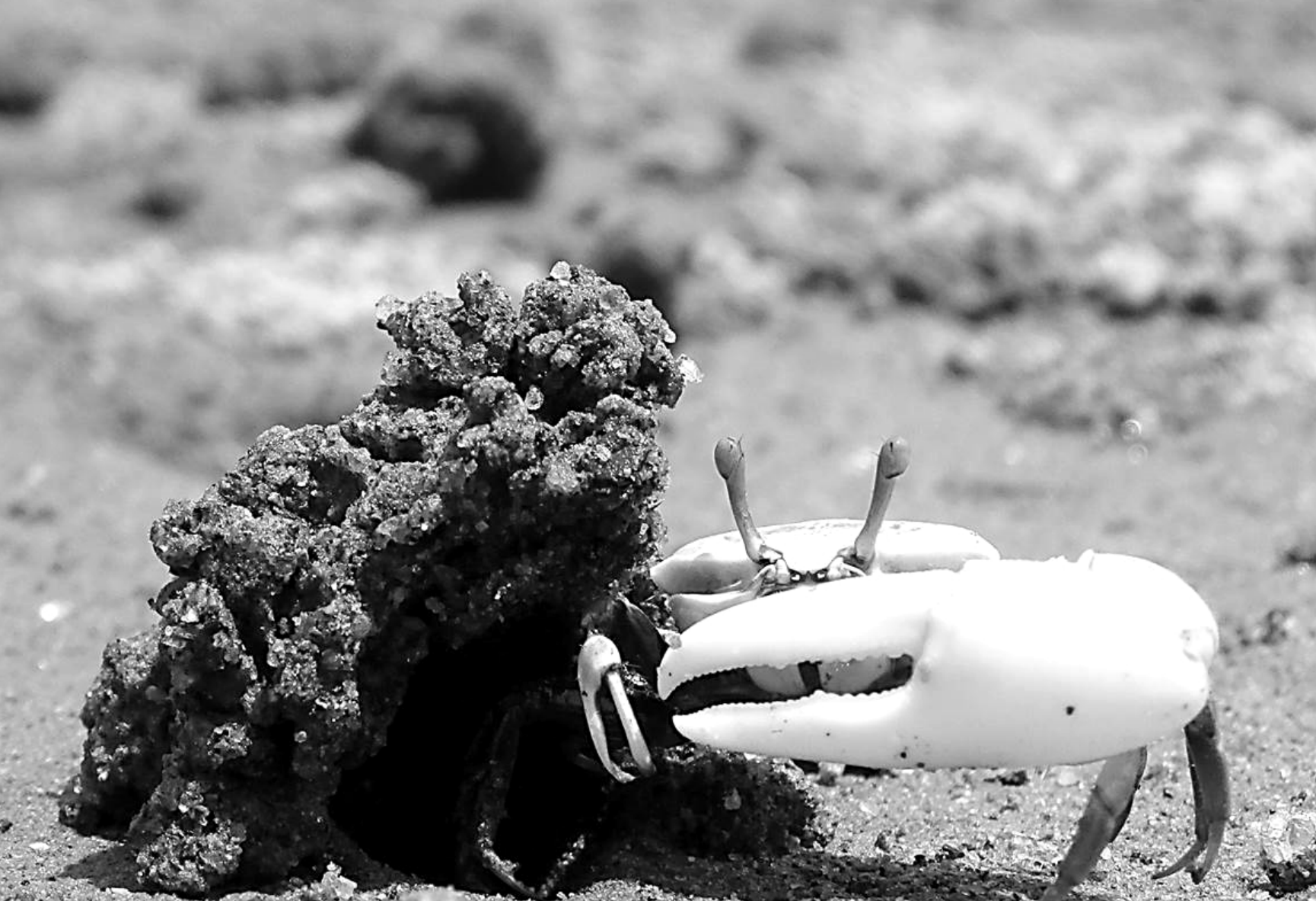

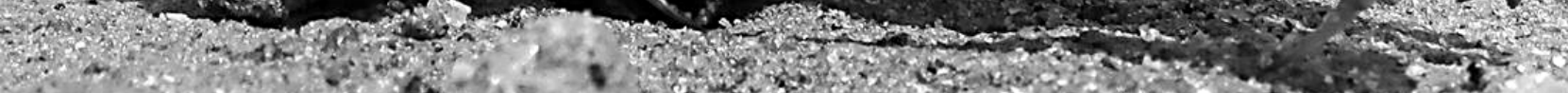

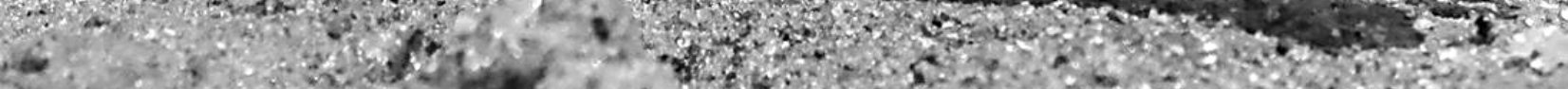

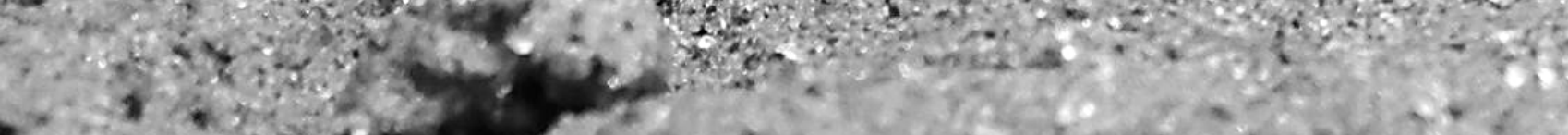

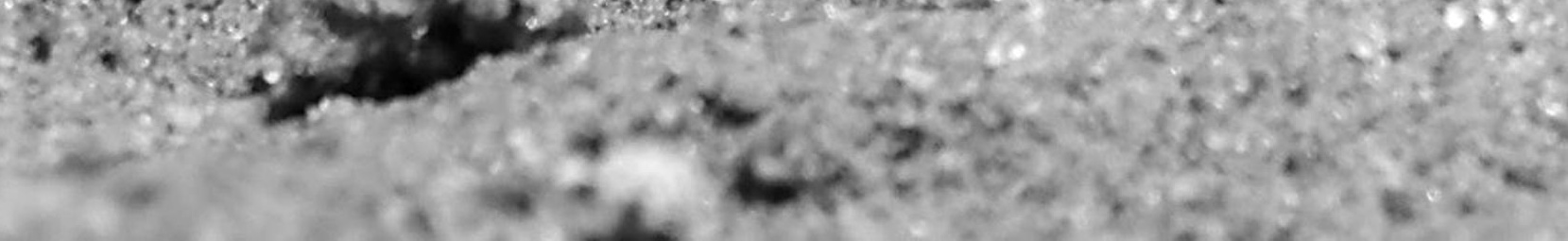




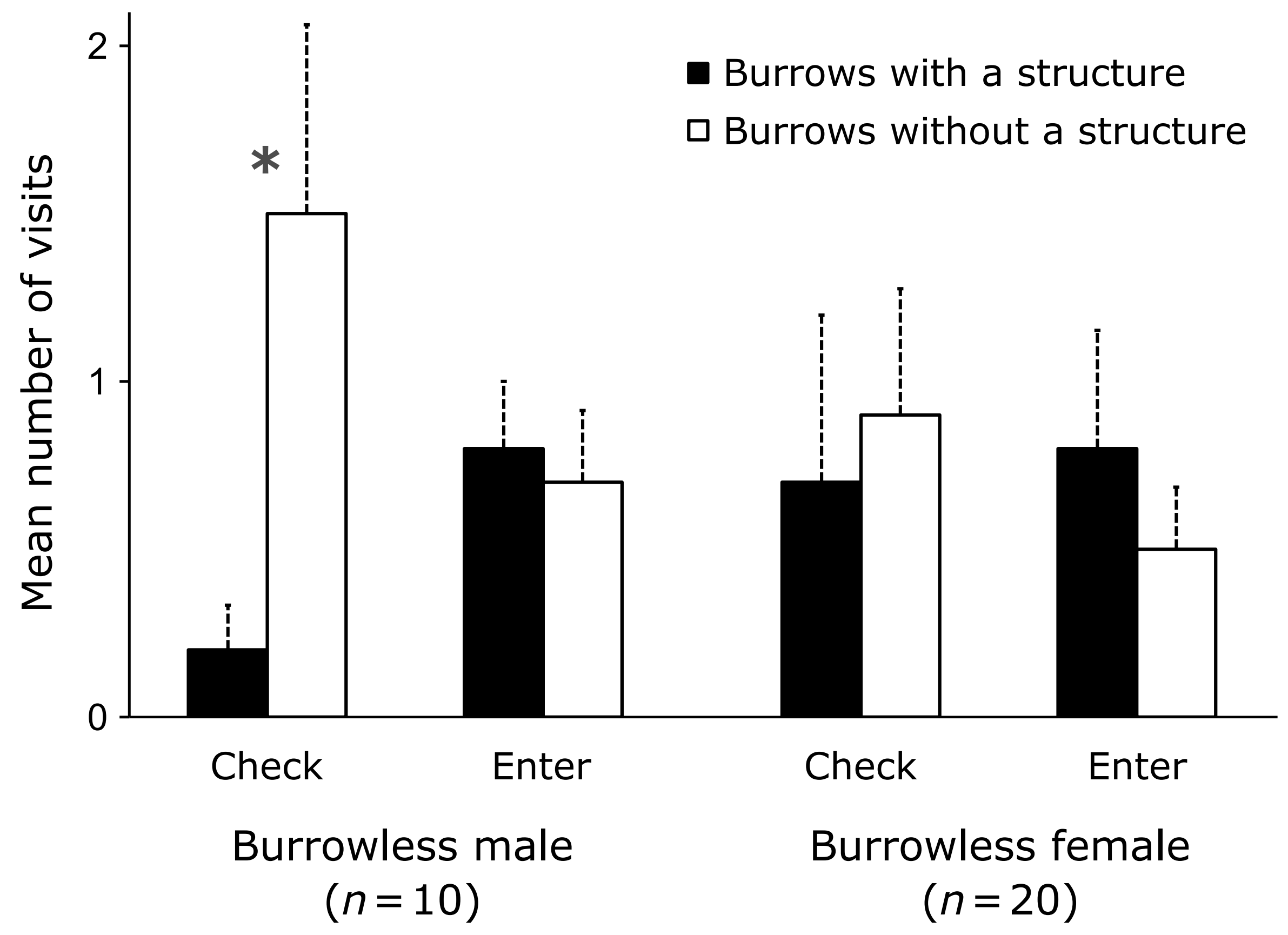

